\title{
Climate change impacts on meteorological drought using SPI and SPEl: case study of Ankara, Turkey
}

DOI:

10.1080/02626667.2019.1691218

\section{Document Version}

Accepted author manuscript

Link to publication record in Manchester Research Explorer

\section{Citation for published version (APA):}

Danandeh Mehr, A., Sorman, A. U., Kahya, E., \& Afshar, M. (2020). Climate change impacts on meteorological drought using SPI and SPEl: case study of Ankara, Turkey. Hydrological Sciences Journal, 65(2), 254.

https://doi.org/10.1080/02626667.2019.1691218

\section{Published in:}

Hydrological Sciences Journal

\section{Citing this paper}

Please note that where the full-text provided on Manchester Research Explorer is the Author Accepted Manuscript or Proof version this may differ from the final Published version. If citing, it is advised that you check and use the publisher's definitive version.

\section{General rights}

Copyright and moral rights for the publications made accessible in the Research Explorer are retained by the authors and/or other copyright owners and it is a condition of accessing publications that users recognise and abide by the legal requirements associated with these rights.

\section{Takedown policy}

If you believe that this document breaches copyright please refer to the University of Manchester's Takedown Procedures [http://man.ac.uk/04Y6Bo] or contact uml.scholarlycommunications@manchester.ac.uk providing relevant details, so we can investigate your claim.

\section{OPEN ACCESS}




\title{
Climate change impacts on meteorological drought using SPI and SPEI: case
}

\section{study of Ankara, Turkey}

\author{
Ali Danandeh Mehr ${ }^{\mathrm{a}^{*}}$, Ali Unal Sorman ${ }^{\mathrm{b}}$, Ercan Kahya ${ }^{\mathrm{c}}$ and Mahdi Hesami Afshar ${ }^{\mathrm{b}}$
}

${ }^{a}$ Civil Engineering Department, Antalya Bilim University, Antalya, Turkey; ${ }^{b}$ Civil Engineering

Department, Middle East Technical University, Ankara, Turkey; ' Hydraulics Division, Civil

Engineering Faculty, Istanbul Technical University, Istanbul, Turkey

*Corresponding author: e-mail: ali.danandeh@antalya.edu.tr, ORCID: 0000-0003-2769-106X

\begin{abstract}
Using regionally downscaled and adjusted outputs of three global climate models (GCMs), meteorological drought analysis was accomplished across Ankara, the capital city of Turkey. To this end, standardized precipitation index (SPI) and standardized precipitation evapotranspiration index (SPEI) were projected under (representative concentration pathway) RCP4.5 and RCP8.5 greenhouse gas scenarios. In general, our results show that Ankara experienced six severe and two extreme drought events during the reference period, 1971-2000. However, the projections indicate fewer drought events for the near future period of 2016-2040, with no potential extreme drought events. While the RCP4.5 scenario showed that dry spells will be dominant in the second half of the near future period, the RCP8.5 scenario projected that dry spells will be evenly distributed during the entire near future period.
\end{abstract}

Keywords drought; SPI; SPEI; CMIP5 experiments; Ankara, Turkey 


\section{Introduction}

Drought detection and monitoring indices that are used to represent drought severity are commonly classified under four categories: meteorological, hydrological, agricultural and socio-economic. Each of these groups of indices requires some identifying variables or parameters, such as precipitation, evaporation and transportation for meteorological drought, soil moisture deficit and evaporation stress for agricultural drought and streamflow shortage or lack of groundwater supplies for hydrological drought indices. To date, a large number of studies have been conducted indicating appropriate drought indices for different case study regions (e.g. Jiang et al. 2015, Meresa et al. 2016, Hesami Afsar 2016, Rhee and Yang 2018, Tosunoglu et al. 2018, Myronidis et al. 2018). If one looks at the index referred to as 'integrated surface drought index' (Wu et al. 2013), the data inputs for model construction are grouped under three main categories, namely:

- Meteorological, hydrological and remote sensing data

- Remote sensing and vegetation data

- Biophysical elements as topographic and morphologic data

To monitor meteorological drought (hereafter MD), meteorological variables/parameters may be used. The associated indices are typically based upon precipitation and temperature data series. There are various MD indices such as the well-known standardized precipitation index (SPI) and the most recently developed standardized precipitation evapotranspiration index (SPEI). Table 1 summarizes some of the commonly used MD indices, their required data and the references where they are described.

Considering the increasing trend in global temperatures and the impact on local climate, it has been pointed out that climate change may alter the frequency and severity of extreme events such as droughts (IPCC 2013). Therefore, drought analysis with respect to the effect of climate 
change has received more attention over recent decades (Blenkinsop and Fowler 2007, Loukas et al. 2008, Dai 2013, Jiang et al. 2015, Wu et al. 2016, Osuch et al. 2016, Grillakis 2019). For example, Loukas et al. (2008) evaluated climate change effects on drought severity in the Thessaly region, Greece, using SPI at multiple time scales and precipitation projections derived by a general circulation model (GCM) under two socio-economic scenarios (Special Report on Emissions Scenarios: SRES A2 and SRES B2). The results revealed that the annual drought severity augmented for the whole of the Thessaly region and SPI time scales, with the A2 emissions scenario being the most extreme. Meresa et al. (2016) showed that temporal drought patterns over selected Polish catchments substantially varied with respect to the type of drought index: while SPEI indicated drier conditions for the future of the catchments, SPI showed wetter climates. In a similar study, Wu et al. (2016) analysed the spatio-temporal patterns of historical and future MD in Beijiang River Basin, South China. Their results showed that drought is projected to become more intense in the basin, especially at its southern region.

Considering the above-mentioned trend in drought analysis under climate change scenarios, the main objective of this study is to compare the current and projected meteorological drought condition across the metropolitan city of Ankara, Turkey, based on the recent climate change scenarios, representative concentration pathways (RCP4.5 and RCP8. $5^{1}$ ). Using SPEI at different time scales, various characteristics of MD at the reference (1970-2000) and the near future period (2016-2040) were extracted for six meteorological stations distributed across the study area. Although there have been a few studies assessing climate change impacts on hydro-meteorological

\footnotetext{
${ }^{1}$ RCP8.5 is a so-called 'worst case' scenario that does not include any specific climate mitigation target. The greenhouse gas emissions and concentrations in this scenario increase considerably over time, leading to a radiative forcing of $8.5 \mathrm{~W} / \mathrm{m}^{2}$ at the end of the century.
} 
drought across Turkey (e.g. Tosunoglu and Can 2016), to the best of our knowledge, this is the first study that uses the SPEI index under RCP scenarios for drought analysis across Ankara. The aim of the study is that the findings will be beneficial for sustainable water resources management in the study region.

\section{Materials and methods}

A single index or multiple indices have been used to monitor and forecast drought in a region. In addition, hybrid indices have been recently proposed to improve the strengths of a variety of data, yet maintain a single index for decision-makers (see Mukherjee 2018 for a perspective of drought indices). Knowing that MD severity is better evaluated on the basis of both temperature and precipitation records/projections, we preferred the SPEI index with short-term (3- and 6-month) and long-term (12-month) accumulation periods in this study. Moreover, spatial-temporal correlation analysis between the SPEI and SPI indices across the study area were carried out for two periods: a reference period with a length of 30 years (1971-2000) and the projection/near future period with a length of 25 years (2016-2040). The meteorological parameters used to derive the drought index include (a) gauge precipitation and air temperature observations for the reference period and (b) bias-corrected precipitation and air temperature projections for the near future period. The former data were obtained from six meteorological stations across the study area and the latter are projected through the dynamic downscaling together with linear transformation of three GCMs outputs to the location of meteorological stations. Details of the meteorological stations and the implemented GCMs are explained in Section2.2. 


\subsection{Overview of the implemented drought indices}

\subsubsection{SPI}

The SPI is a multi-scalar probabilistic index that calculates precipitation deficiency during wet and dry spells and allows drought monitoring at different time scales (McKee et al. 1993). This index was underlined by the World Meteorological Organization as a starting point for MD monitoring and has been used in a large number of previous studies because of its simplicity, monthly data requirement and it is commonly accepted on a wider scale. The calculation is done using long-term (typically 30-year) monthly precipitation data that are fitted to a probability distribution function such as Gamma or Pearson Type III. Any percentile from the selected distribution model is considered to be same as the percentile on a Gaussian distribution function and the corresponding $Z$ score is determined as the value of the SPI. The values are then used to find drought characteristics, such as duration, intensity and severity. Based upon the SPI classification (McKee et al. 1993), values in the ranges -1.49 to $-1.0,-1.5$ to -1.99 and $\leq-2.0$ indicate moderate, severe and extreme drought conditions, respectively. However, various drought intensity classes are also available in the literature based upon different SPI thresholds.

\subsubsection{SPEI}

The SPEI is a relatively new MD index that combines the advantages of SPI with temperature variability. It was proposed in order to be more suitable for drought monitoring and analysis under climate change (Jiang et al. 2015, Ahmadalipour et al. 2017, Wang et al. 2019). A detailed description of calculation procedure is presented in a seminal paper by Vicente-Serrano et al. (2010). In order to calculate the SPEI, one may first calculate the monthly potential 
evapotranspiration (PET) and the difference in monthly water balance of a given month (i.e. deficit $\left.D_{i}\right)$ is then computed by subtracting PET from precipitation value of a given month $\left(P_{i}\right)$.

$$
D_{i}=P_{i}-\mathrm{PET}_{i}
$$

The standardized deficit time series is fitted to a log-logistic probability distribution function and the SPEI value is then calculated as the standardized values of cumulative probability of $D_{i}$, as follows:

$$
\begin{gathered}
\mathrm{SPEI}_{i}=W_{i}-\frac{2.515517+0.802853 W_{i}+0.010328 W_{i}^{2}}{1+1.432788 W_{i}+0.189269 W_{i}^{2}+0.001308 W_{i}^{3}} \\
W_{i}=\sqrt{-2 \ln p} \quad \text { for } p \leq 0.5 \quad \text { (3a) } \\
W_{i}=\sqrt{-2 \ln (1-p)} \quad \text { for } p>0.5 \quad(3 \mathrm{~b})
\end{gathered}
$$

where $p$ is the probability of exceeding a given $D_{i}$ and the sign of the resultant SPEI is reversed for $p>0.5$.

\subsubsection{SPI vS SPEI}

The sensitivity of SPEI to PET calculation and probability distribution methods has been explored by Stagge et al. (2014) and Stagge et al. (2015), respectively. While the Thornthwaite equation (to calculate PET) and log-logistic distribution (to normalize the index) are used in the original SPEI methodology, application of other methods such as the modified Penman-Monteith equation (to calculate PET; see Ahmadalipour et al. 2017) and the generalized extreme value distribution (to normalize the index) have also been recommended (e.g. Stagge et al. 2015).

Although the application of multiple indices provides supportive tools for decision makers, incomparable scales of thresholds must be carefully taken into account by an analyst. This problem 
exists not only for the thresholds and classification percentage, but also for the meaning of values of indices. For instance, as pointed out by Şen (2015), "a severe drought occurs $4.4 \%$ of the time for the SPI, $5 \%$ for the PDSI, but $12 \%$ for the SWSI (surface water supply index) with the same verbal description." Considering the SPI and SPEI indices together; for example, a value of 0.0 for SPI stands for $50 \%$ of cumulative probability of a precipitation event, which corresponds to the same cumulative probability of deficit (Eq. (1)) regarding SPEI provided that there is no consistency between their cumulative density functions (cdfs). As previously mentioned, cumulative probabilities in SPI refers to areas under the standard normal distribution; however, corresponding cumulative probability in SPEI is determined by the log-logistic distribution.

No definite thresholds for the SPEI values and associated drought conditions were presented by Vicente-Serrano et al. (2010). Meresa et al. (2016) and Rhee and Im (2017) classified SPEI values with the thresholds suggested by McKee et al. (1993), regardless of the aforementioned inconsistencies. Jiang et al. (2015) also classified drought conditions with identical thresholds for SPI and SPEI values. To overcome the confusion caused by different cdfs, we considered each index completely independently from the other and obtained some SPEI thresholds for a set of specified probability of exceeding of $D_{i}$ using Eq. (2). Figure 1 compares the residuals between indices at the cumulative probabilities of interest. It is clear from the residual line in Fig. 1 that both indices are more or less equal within the range $0.15-0.85$ of cumulative probabilities. The range covers index values between -1 and +1 . Thus, it can be concluded that both rainfall and deficit have the same cumulative probability of occurrence for normal and near normal drought conditions. It is also clear that the differences increase at infrequent drought probabilities. Thus, the corresponding thresholds for these indices for both wet and dry periods were calculated; the results are summarized in Table 2. 


\subsection{Study area and observed data}

The study area is the metropolitan city of Ankara, located in central Anatolian region of Turkey (Fig. 2). According to the Koppen-Geiger climate classification, the study area has a hot and dry summer Mediterranean climate with cool winters. On the basis of the last 90 years of observations, the average annual precipitation is around $387 \mathrm{~mm}$, which indicates an arid and semi-arid longterm climate. The Ankara Province, with total area of approximately $25000 \mathrm{~km}^{2}$, encompasses six meteorological stations, namely, Beypazari, Esenboga, Kecioren, Kizilcahamam, Nallihan and Polatli, that are maintained and operated by the Turkish General Directorate of Meteorology. These are the stations that have long-term precipitation and temperature observations (see Fig. 2) with proved data quality (Hesami Afshar et al. 2016). In this study, historical (i.e. 1971-2000) precipitation and temperature measurements at these stations were used to calculate climate indices for the reference period, as well as to adjust inevitable biases of the GCM-driven regional climate model (RCM) outputs.

\subsection{Climate models and projected data (2016-2040)}

The historical simulations and projections of future changes in precipitation and temperature over Ankara were derived using RCM output from the project "Climate Projections for in and around Turkey" (Demircan et al. 2014). This project used the RCM RegCM4.3.4 (Pal et al. 2007) to acquire a series of high-resolution simulations of three GCMs, generating stationary climate simulations for both the control (1971-2000) and future (2016-2099) time periods. Major highlights of the GCMs used in the project are listed in Table 3. It should be noted that these were selected among those of the Coupled Model Intercomparison Project Phase 5 (CMIP5) GCM 
experiments, so that they provide the closest mean temperature for Turkey in the control period (Demircan et al. 2014). Detailed information about the project and relevant downscaling process is also given by Akçakaya et al. (2015). A brief review of the GCMs used in this study is presented herein. The spatial distribution of the RCM grid points covering the study area, at a spatial resolution of $20 \mathrm{~km}$, is shown in Fig. 2.

\subsubsection{Hadley Centre Global Environment Model 2 - Earth System (HadGEM2-ES)}

The HadGEM2-ES GCM is a full Earth-system model that has been used by the UK Met Office Hadley Centre for the CMIP5 experiments. The HadGEM family of Earth-system models consists of different model configurations with different complexity but using an identical physical framework. The HadGEM2-ES comprises a coupled atmosphere-ocean configuration, with or without a vertical extension in the atmosphere to include a well-resolved stratosphere. The Earthsystem configuration has the terrestrial and ocean carbon cycle and tropospheric chemistry components (Collins et al. 2011). Terrestrial vegetation and carbon are represented by the dynamic global vegetation model, which simulates the coverage and carbon balance of five vegetation types. The relevant global atmospheric model runs at N96 horizontal resolution $\left(1.25^{\circ}\right.$ latitude $\times 1.875^{\circ}$ longitude) with 38 vertical levels (L38) and a 30-min time step. The ocean component of the model has a 1-degree horizontal resolution (increasing to 1/3 degree at the Equator) and 40 vertical levels and the Earth system. More details on HadGEM2 can be found in Martin et al. (2011).

\subsubsection{Max-Planck-Institute Earth System Model (MPI-ESM)}

The new MPI-ESM is a comprehensive coupled GCM that consist of components for the ocean, the atmosphere and the land surface. This model originally evolved from the components of 
ECHAM6 for atmosphere and MPIOM for ocean and sea ice, as well as JSBACH for the terrestrial biosphere, and optionally includes dynamical land vegetation (DYNVEG) and marine biogeochemistry (HAMOCC). In addition to the inclusion of these components, the carbon cycle has been added to the model system. This constitutes the significant difference between MPI-ESM and its predecessor model ECHAM5/MPIOM. The MPI-ESM has been developed for a variety of configurations differing in resolution of ECHAM6 or MPIOM or set-up of orbit and vegetation. The mixed resolution (MR) configuration of MPI-ESM (MPI-ESM-MR), which is running on 95 atmosphere level and 0.4-degree horizontal grid spacing, was used for a wide range of CMIP5 simulations. A detailed description of the model is presented in Giorgetta et al. (2013).

\subsubsection{Geophysical Fluid Dynamics Laboratory Earth System Model (GFDL-ESM2M)}

The GFDL-ESM2M is a global coupled climate-carbon Earth-system model developed at the National Oceanic and Atmospheric Administration (NOAA) in the USA. The physical ocean component of GFDL-ESM2M uses Modular Ocean Model version 4p1 with vertical pressure layers comprising the thermocline depth being relatively deep compared to observations. The crucial role of ocean dynamics on climate variability in the model was highlighted by overly strong El Niño-Southern Oscillation. Thus, it might better represent climate changes relating to surface circulation given its superior surface temperature, salinity and height patterns, tropical Pacific circulation and variability and Southern Ocean dynamics. For further information about the model, the reader is referred to Dunne et al. (2012). 


\subsection{Uncertainties of climate models}

One of the major challenges of climatic change impact studies is the evolution of uncertainties by modelling the Earth system over long-term scenarios (Wu et al. 2015, Danandeh Mehr and Kahya 2017b, Xu et al. 2019). In order to project a drought index into the future, three major types of uncertainty were taken into account in this study. The first uncertainty that comes from the GCMs employed is due to the limits of our scientific knowledge to model chaotic interactions between the diverse components of the climatic system. Thus, an ensemble of three GCMs was adopted in this study to derive the near future drought indices. The second uncertainty originates from emissions scenarios and is associated with socio-economic development, which significantly alters the composition of the atmosphere and is an important factor in climate change. To deal with this uncertainty, two recent greenhouse gas concentration trajectories (RCP4.5 and RCP8.5) were adopted and analysed separately in this study. The third uncertainty depends on the choice of downscaling/bias-correction method. In brief, a two-step bias-correction method (Step 1: GCMRCM calibration using reanalysis data, and Step 2: grid-based pattern-oriented bias correction using historical gauge observations) was used in this study and is described below.

To calibrate the GCM-RCM combinations, the climatic outputs of the initial runs were compared with high-resolution observed reanalysis data from the Climate Research Unit (CRU) University of East Anglia, UK, and the University of Delaware (UDEL), USA, for the reference period; then, new threshold values were determined for grids to get better results for the calibration period. The HadGEM-Reg4 results indicated a reasonable fit between the model and observed temperatures, especially for summer and winter; however, for spring and autumn, the model results were found to be somewhere between 1.5 and $2{ }^{\circ} \mathrm{C}$ below the associated observed data. Regarding the precipitation pattern, the model results overlapped with the observed data, especially for the 
winter. For the spring and autumn, the model reproduced higher values than those of the observations. The best calibrated MPI-Reg4 model was found to reveal an annual average difference between the model and observed temperatures within the range $0.5-1.0^{\circ} \mathrm{C}$ across Turkey. When the precipitation values are examined, the model results show similar values to the observed ones for all seasons. It was also seen that the annual average values are close to each other and to the CRU observation data, but about $8 \%$ lower than the UDEL reanalysis observations. According to the results of the best GFDL-Reg4 for the 1971-2000 period, the model shows lower averages than observed temperatures for all seasons. When the precipitation values are explored, the model results show lower estimations than observed values for winter and autumn, while the results for spring and summer are higher than observed values. Although these are the best calibrated models, the overall calibration results indicated varying uncertainty for different seasons.

Since the climate models were calibrated with the grid-based methodology across Turkey, the parameterization procedure tries to correct the values in a region where we had weekly results, but it could affect other regions where reasonable results can get worse. For this reason, a gridbased, pattern-oriented bias correction was also applied on the model outputs (here precipitation and temperature only), as suggested in the literature (e.g. Nazemosadat et al. 2016, Danandeh Mehr and Kahya 2017). Using the climate data from a local gauge station and the nearby grid point to the gauge, the bias-correction procedure can find an adjusting factor so that the modeller is able to match the monthly mean and variance of a pair of observed and simulated precipitation and temperature series over the historical period (1971-2000). Then, the future projections of the model at the grid point of interest are adjusted using the corresponding bias-correction factor. For example, historical observations at Polatli and Beypazari stations were used to modify model outputs at grid\#2531 and grid\#2830, respectively (see Fig. 1). Comparing to the other classic biascorrection methods (e.g. see Fang et al. (2015) for a comparison of different methods), Danandeh 
Mehr and Kahya (2017a) demonstrated that the grid-based, pattern-oriented method has the advantage of lower computation costs as it uses monthly series to match long-term means of observed and simulated data, whereas classic methods typically use daily observations to correct GCM/RCM outputs day-by-day.

\section{Results and discussion}

\subsection{Drought characteristics in the reference period (1971-2000)}

To calculate the SPI and SPEI values in this study, we used the SPI and SPEI packages available at Comprehensive R Archive Network ${ }^{2}$. While the former uses gamma distribution, the latter uses log-logistic distribution by default, and we followed this initial set up. Potential evapotranspiration was also obtained based on the Thornthwaite method in the calculation of SPEI. As with SPI, the SPEI values at 3-, 6- and 12-month time scales for all the meteorological stations were calculated at the reference period; the results are presented in Fig. 3 and Fig. 4, respectively. A comparison of the temporal patterns of these indices at a given station indicates that wet and dry conditions did not necessarily occur in the same months. For example, the SPI-3 pattern for Beypazari shows seven extreme drought (ED) events, while the SPEI-3 pattern indicates three ED events during the reference period. The SPI uses only precipitation, whereas the SPEI is based on both precipitation and PET. Therefore, drought features are investigated further using the SPEI having the highest correlation with the SPI pattern. To realize the most correlated patterns, a Pearson correlation matrix was calculated for the 3-, 6- and 12-month lags between the indices at each station (Fig. 5).

As expected, the SPI was highly correlated to the SPEI at all the stations for all time scales, with the values fluctuating between 0.90 and 0.97 . The correlations between these indices at

\footnotetext{
${ }^{2}$ http://sac.csic.es/spei/tools.html
} 
western stations (Beypazari, Nallihan and Polatli; Fig. 2) were relatively lower than those of eastern stations (Kecioren, Kizilcahamam and Esenboga). This pattern is likely due to the higher mean annual air temperature (approx. $12.1^{\circ} \mathrm{C}$ ) at the western stations, compared to that of the eastern stations (approx. $\left.10.4^{\circ} \mathrm{C}\right)$. The highest correlation $(0.9654)$ was obtained for the 6-month time lag at Kizilcahamam and the lowest (0.898) for the 12-month time lag at Beypazari station. From the spatial variation perspective, our results show that the correlations between the SPI of a given station and SPEI of other stations typically varies within the higher range of 0.6 to 0.9 , apart from Nallihan station. The higher the correlations, the shorter the time scale, which concurs with previous studies (Vicente-Serrano et al. 2010; Jiang et al. 2015). At Nallihan station, the values of correlation were dramatically decreased and varied within the lower range of $0.17-0.55$, where the long-term mean of total monthly precipitation $(23.5 \mathrm{~mm})$ is significantly different compared to the other stations and markedly deviates from the study area average $(33.5 \mathrm{~mm})$ during the reference period (1971-2000).

Regarding the SPEI-6 patterns, the characteristics of historical drought events are summarized in Table 4 and graphically presented in Fig. 6 . Table 4 indicates that 17 moderate (MoD), six severe (SD) and two extreme drought (ED) cases occurred within the 30-year reference period. The first ED occurred in 1989 lasting for four months (starting in summer and ending at the beginning of autumn) and the second ED event happened in 1994 lasting for two months (within autumn). The average air temperature ranged around $20.5^{\circ} \mathrm{C}$. Comparing the average temperatures under $\mathrm{MoD}$ and $\mathrm{SD}\left(11^{\circ} \mathrm{C}\right.$ and $10^{\circ} \mathrm{C}$, respectively), one can conclude that summer/autumn air temperature is the main contributor to the occurrence of ED events. But MoD events occurred in all seasons, either in hot autumns $\left(T=27^{\circ} \mathrm{C}\right)$ or cold winters $\left(T=0^{\circ} \mathrm{C}\right)$. They generally lasted for short periods (one month is predominant). The SD and ED events occurred mainly between 1989 and 1994, with an average severity of -1.5 to -2.0 . 


\subsection{Drought characteristics of the near future period (2016-2040)}

As previously mentioned, the grid outputs of three GCM-RCM combinations, namely HadGEMReg4, MPI-Reg4 and GFDL-Reg4, were used in this study to obtain projected precipitation and temperature (and consequently SPEI index) time series for the near future period (2016-2040). Figure 7 and Fig. 8 display how the row climate models estimated observed monthly temperature and precipitation, respectively, at the meteorological stations. Differing largely from each other, the GCM-RCM models show different efficiency at each grid. However, all are capable of capturing the observed monthly trend. They generally underestimate the average monthly temperature and overestimate corresponding precipitation values. Their efficiency in terms of longterm mean of root mean square error (RMSE) is given in Fig. 9.

As previously declared, historical gauge observations were used through a grid-based, pattern-oriented bias correction procedure (Danandeh Mehr and Kahya 2017a) to adjust GCMRCM outputs. Owing to the important effect of the statistical distribution of historical monthly precipitation and temperature series on future SPEI projections, the efficiency of the biascorrection method used was assessed by comparing the cdfs of the observed, raw ensemble and bias-corrected ensemble simulations for the reference period. As expected, the results show that the bias-correction procedure matches temperature cdfs perfectly and successfully adjusts precipitation cdfs. Examples of cdf curves for Polatli and Kecioren stations are depicted in Fig. 10.

Using the bias-corrected precipitation and temperature at the closest grid points to each station (except Nallihan station where the average of climate outputs at grids \#2827 and \#2828 was used), SPEI time series were obtained for different time scales. Ensemble projected SPEI-6 values for all the meteorological stations are presented in Fig. 11. With respect to the projected SPEI-6 patterns under the RCP4.5 scenario at all the stations, it is observed that dry spells are expected to 
occur during the second half of the near future period (i.e. 2029-2040). They are projected to occur more or less in the same months, but none of them are ED events (SPEI $\leq-1.83$ ). Regarding the results under the RCP8.5 scenario, significant change is projected to occur in the temporal variation of drought events so that both short and long-lasting dry spells are expected during the entire near future period at all stations, excluding Polatli. Surprisingly, this is in contrast with the RCP4.5 projections for that station. With respect to the projected SPEI-6 patterns, the characteristics of the future drought events, together with the projected mean air temperature under RCP4.5 and RCP8.5 scenarios over the entire study area, are summarized in Table 5. A graphical presentation is given in Fig. 12.

Table 5 indicates that no potential ED event is projected in the near future period; however, five and nine MoD events are expected to take place in the near future period under RCP4.5 and RCP8.5 scenarios, respectively. With reference to the RCP4.5 projections, the first SD is projected to occur in October 2037, lasting one month, and the second SD event is expected to happen at the beginning of the following year, lasting two months. In comparison with the results for the reference period, one can expect a significant decrease in the frequency and intensity of SD events. Similarly, regarding the RCP8.5 projections, the first SD is projected to occur in the entire summer and autumn of 2016, while the second SD event is expected to happen at the beginning of spring 2037, lasting one month. In regard to the observed monthly temperature and precipitations data (obtained during the present study) and corresponding SPEI values in 2016 (Fig. 13), the province does not experience SD conditions to occur, which is inconsistent with the RCP8.5 projections, while it is in agreement with the RCP4.5 projections. 


\subsection{Seasonal comparison of model results for the reference and future periods}

A seasonal comparison between drought characteristics for the reference and near future periods is presented in Table 6, in which the projected period includes both the RCP4.5 and RCP8.5 scenarios. A striking finding is that the most frequent SD events took place during one reference interval: 1993-1995. The future SD drought events are expected to occur during two different future time intervals: 2031-2033 and 2036-2038. It is evident from Table 6 that the number of MoD events $(N)$ in the reference period during the winter is seven, dropping to four in the autumn. The average severity value $(S)$ varies between -1.08 and -1.22 . Meanwhile, the recorded air temperature for winter and autumn months is in the range $3.7-5.4{ }^{\circ} \mathrm{C}$. In contrast, the air temperature in spring and summer months are 12.4 and $23.0^{\circ} \mathrm{C}$, respectively. For the SD case, two to three events are expected, with an average severity of -1.56 to -1.70 . The air temperature in winter and autumn is 2.2 and $3.7^{\circ} \mathrm{C}$, respectively, whereas it increases to $23.6^{\circ} \mathrm{C}$ in the summer months. Considering the ED events, the average severity has a value of around -2.05 with an average air temperature of $20.5^{\circ} \mathrm{C}$.

Under the RCP4.5 assumption, the LD of MoD events varies from 1 to 6 months, with an average severity of -1 to -1.27 and average air temperature of $5.9^{\circ} \mathrm{C}$. For the SD events, these occur within 1 and 2 months, with an average severity of -1.5 and a temperature of $5^{\circ} \mathrm{C}$. When we consider the RCP8.5 scenario, the LD of MoD events varies between 1 and 5 months during winter and spring, with a severity of -1.28 and air temperature of $9.6^{\circ} \mathrm{C}$. During the autumn the intensity drops to -1.1 and temperature increases to $20.5^{\circ} \mathrm{C}$. The LD of SD events varies between 1 and 6 months during winter, summer and autumn as the severity increases to -1.6 and the projected air temperature becomes $15^{\circ} \mathrm{C}$. It is important to note that no ED events is expected to occur. 


\section{Conclusion}

In comparing the SPI and SPEI, the latter drought index was decided as an analysis tool to investigate the current (1970-2000) and near future (2016-2040) characteristics of drought events across Ankara Province (Turkey) using observed and projected data from six meteorological stations. Climate projections under RCP4.5 and RCP8.5 scenarios were obtained from the regional downscaling of three GCMs (HadGEM2-ES, MPI-ESM-MR and GFDL-ESM2M) under CMIP5 experiments, which were already available from the most appropriate global models to simulate the climate of Turkey and its surroundings. Using the observed and reproduced data from the reference period, the projected precipitation and air temperature time series were adjusted before calculating the near future SPEI. The results may be summarized as follows:

- Although the SPI and SPEI are highly correlated at all the stations for all time scales, they may produce different numbers of events for each drought category. This is due not only to the influence of PET associated with SPEI, but also to the difference in their cumulative density functions (cdf) resulting in different thresholds (Table 2) and, consequently, a difference in the number of severe (SD) and extreme (ED) events is expected. As a result, we strongly suggest to consider SPEI in future applications.

- In respect to the SPEI-6 pattern, which shows the highest correlation $(R=0.97)$ with SPI, Ankara Province experienced six SD and two ED cases during the period 1971-2000. Moreover, the ED events occurred during hot spring and summer seasons.

- Differing markedly from each other, each of the implemented GCM-RCM combinations showed different efficiency at each meteorological station. Despite its underestimation, the HadGEM-Reg4 model combination was the best air temperature simulator for Ankara 
Province, whereas GFDL-Reg4 appeared to be the most appropriate model combination for reproducing precipitation.

- Finally, regarding the projected SPEI-6 patterns under the RCP4.5 scenario, dry spells are expected to occur in the second half of the near future period, while the results for the RCP8.5 scenario show dry spells are anticipated across the entire near future period. There is no expectation for ED events in either scenario.

Over the course of the past few years, climatologists have suggested an increased risk of drought in the 21st century (Dai 2012; Dai et al. 2018). There are, however, large differences in the frequency, intensity and drying patterns in different regions (Dai 2011, Van Lanen et al. 2013). From a global perspective, conflicting results of how drought is changing under climate change have also been published (Sheffield et al. 2012; Trenberth et al. 2013; Dai et al. 2018). The reasons behind such contradictory conclusions may originates from the use of different metrics of drought, the ways of estimating the identifying parameters of the metrics and also uncertainties present in the underlying climate models/scenarios. From a meteorological perceptive, our results are in agreement with those of Burke et al. (2006), in which projected PDSI analysis showed a wetter climate for the near future period over central Africa, eastern Asia and high northern latitudes. Our conclusions are also similar to those of Meresa et al. (2016), in which the projected SPI analysis revealed lower probability of future drought events over selected Polish catchments. 


\section{Acknowledgements}

The authors would like to thank the General Directorate of Meteorology (MGM) of Turkey for providing the meteorological datasets. We are also grateful to Dr Anne Van Loon (Associate Editor) and two reviewers for providing constructive comments on the initial version of this paper.

\section{References}

Ahmadalipour, A., Moradkhani, H. and Demirel, M.C., 2017. A comparative assessment of projected meteorological and hydrological droughts: Elucidating the role of temperature. Journal of Hydrology, 553, 785-797.

Akçakaya, A., Sümer, U.M., Mesut Demircan, M., et al., 2015. Climate projections and climate change in Turkey based on new scenarios. Bureau of research, Turkish state meteorological Service, pp150. (In Turkish)

Bhalme, H.N. and Mooley, D.A., 1980. Large-scale droughts/floods and monsoon circulation. Monthly Weather Review, 108(8), 1197-1211.

Blenkinsop, S. and Fowler, H.J. 2007. Changes in drought frequency, severity and duration for the British Isles projected by the PRUDENCE regional climate models. Journal of Hydrology, 342(1-2), 50-71.

Burke, E. J., Brown, S. J. and Christidis, N., 2006. Modeling the recent evolution of global drought and projections for the twenty-first century with the Hadley Centre climate model. Journal of Hydrometeorology, 7(5), 1113-1125.

Byun, H.R. and Wilhite, D.A., 1996. Daily quantification of drought severity and duration. Journal of Climate, 5, 1181-1201.

Collins, W.J. et al., 2011. Development and evaluation of an Earth-System model-HadGEM2. Geoscientific Model Development, 4(4), 1051-1075.

Dai, A., 2011. Drought under global warming: a review. Wiley Interdisciplinary Reviews: Climate Change, 2(1), 45-65.

Dai, A., 2013. Increasing drought under global warming in observations and models. Nature Climate Change, 3(1), 52.

Dai, A., Zhao, T. and Chen, J., 2018. Climate Change and Drought: a Precipitation and Evaporation Perspective. Current Climate Change Reports, 4(3), 301-312. 
Danandeh Mehr, A. and Kahya, E. 2017a. Climate change impacts on catchment-scale extreme rainfall variability: Case Study of Rize Province, Turkey. Journal of Hydrologic Engineering, 22(3), 05016037.

Danandeh Mehr, A. and Kahya, E. 2017b. Grid-based performance evaluation of GCM-RCM combinations for rainfall reproduction. Theoretical and Applied Climatology, 129(1-2), 47-57.

Demircan, M., et al., 2014. Climate change projections for Turkey with new scenarios. In The Climate Change and Climate Dynamics Conference-2014-CCCD2014 (pp. 8-10).

Dunne, J.P., et al., 2012. GFDL's ESM2 global coupled climate-carbon earth system models. Part I: Physical formulation and baseline simulation characteristics. Journal of Climate, 25(19), 6646-6665.

Fang, G., et al., 2015. Comparing bias correction methods in downscaling meteorological variables for a hydrologic impact study in an arid area in China. Hydrology and Earth System Sciences, 19(6), 2547-2559.

Gibbs, W.J. and Maher, J.V., 1967. Rainfall Deciles as Drought Indicators. Bureau of Meteorology Bulletin No. 48, Melbourne, Australia.

Giorgetta, M.A., et al., 2013. Climate and carbon cycle changes from 1850 to 2100 in MPIESM simulations for the Coupled Model Intercomparison Project phase 5. Journal of Advances in Modeling Earth Systems, 5(3), 572-597.

Grillakis, M.G. 2019. Increase in severe and extreme soil moisture droughts for Europe under climate change. Science of The Total Environment, 660, 1245-1255.

Jiang, R., et al., 2015. Use of four drought indices for evaluating drought characteristics under climate change in Shaanxi, China: 1951-2012. Natural Hazards, 75(3), 2885-2903.

Hesami Afshar, M., Sorman, A.U. and Yilmaz, M.T., 2016. Conditional copula-based spatialtemporal drought characteristics analysis—a case study over Turkey. Water, 8(10), 426.

IPCC, 2013. Climate change 2013: the physical science basis. Contribution of Working Group I to the Fifth Assessment Report of the Intergovernmental Panel on Climate Change, Cambridge University Press, Cambridge UK; New York, USA.

Loukas, A., Vasiliades, L. and Tzabiras, J. 2008. Climate change effects on drought severity. Advances in Geosciences, 17, 23-29.

McKee, T.B., Doesken, N.J. and Kleist, J., 1993. The relationship of drought frequency and duration to time scales. In Proceedings of the International $8^{\text {th }}$ Conference on Applied Climatology. American Meteorological Society, Anaheim, CA, USA, 17-22 January. pp. 179-184. 
Martin, G.M. et al., 2011. The HadGEM2 family of Met Office Unified Model climate configurations. Geoscientific Model Development, 4, 723-757.

Meresa, H. K., Osuch, M. and Romanowicz, R., 2016. Hydro-meteorological drought projections into the 21-st century for selected Polish catchments. Water, 8(5), 206.

Mukherjee, S., Mishra, A. and Trenberth, K.E., 2018. Climate change and drought: a perspective on drought indices. Current Climate Change Reports, 4, 145-163.

Myronidis, D., et al., 2018. Comparison of ten notable meteorological drought indices on tracking the effect of drought on streamflow. Hydrological Sciences Journal, 63(15-16), 20052019.

Nazemosadat, M.J., et al., 2016. Projection of temperature and precipitation in southern Iran using ECHAM5 simulations. Iranian Journal of Science and Technology, Transactions A: Science, 40(1), 39-49.

Osuch, M., Romanowicz, R. J., Lawrence, D. and Wong, W. K., 2016. Trends in projections of standardized precipitation indices in a future climate in Poland. Hydrology and Earth System Sciences, 20(5), 1947-1969.

Pal, J.S., et al., 2007. Regional climate modeling for the developing world: the ICTP RegCM3 and RegCNET. Bulletin of the American Meteorological Society, 88(9), 1395-1410.

Palmer, W.C., 1965. Meteorological Drought, Weather Bureau Research Paper No. 45, U.S. Department of Commerce, Washington, D.C.

Palmer, W.C., 1968. Keeping track of crop moisture conditions, nationwide: The new crop moisture index. Weatherwise, 21 (4): 156-161.

Rhee, J. and Im, J., 2017. Meteorological drought forecasting for ungauged areas based on machine learning: Using long-range climate forecast and remote sensing data. Agricultural and Forest Meteorology, 237, 105-122.

Rhee, J. and Yang, H., 2018. Drought Prediction for Areas with Sparse Monitoring Networks: A Case Study for Fiji. Water, 10(6), 788.

Sheffield, J., Wood, E. F. and Roderick, M. L., 2012. Little change in global drought over the past 60 years. Nature, 491(7424), 435.

Trenberth, K. E., Dai, A., Van Der Schrier, G., Jones, P. D., Barichivich, J., Briffa, K. R. and Sheffield, J., 2014. Global warming and changes in drought. Nature Climate Change, 4(1), 17. 
Stagge J.H., et al., 2014. Standardized Precipitation-Evapotranspiration Index (SPEI): sensitivity to potential evapotranspiration model and parameters. Hydrology in a Changing World: Environmnetal and Human Dimensions. In Proceedings of FRIEND-Water 2014, Daniell TM (ed). Montpellier, France, 7-10 October 2014. IAHS Publ. No. 363, IAHS Press, Centre for Ecology and Hydrology: Wallingford, UK, 367-373.

Stagge, J.H., et al., 2015. Candidate distributions for climatological drought indices (SPI and SPEI). International Journal of Climatology, 35(13), 4027-4040.

Şen, Z. 2015. Applied drought modeling, prediction and mitigation. Elsevier.

Tosunoglu, F. and Can, I., 2016. Application of copulas for regional bivariate frequency analysis of meteorological droughts in Turkey. Natural Hazards, 82(3), 1457-1477.

Tosunoglu, F., Can, I. and Kahya, E., 2018. Evaluation of spatial and temporal relationships between large-scale atmospheric oscillations and meteorological drought indexes in Turkey. International Journal of Climatology, 38(12), 4579-4596.

Van Lanen, H. A., Van Loon, A. F., Van Huijgevoort, M. H., Wanders, N., Alderlieste, M. A., Stahl, K., \& Tallaksen, L. M. (2013, April). Past and future hydrological drought in water-scarce European regions. In EGU general assembly conference abstracts (Vol. 15).

Vicente-Serrano, S.M., Beguería, S. and López-Moreno, J.I., 2010. A multiscalar drought index sensitive to global warming: the standardized precipitation evapotranspiration index. Journal of climate, 23(7), 1696-1718.

Wang, Y., Liu, G. and Guo, E., 2019. Spatial distribution and temporal variation of drought in Inner Mongolia during 1901-2014 using Standardized Precipitation Evapotranspiration Index. Science of The Total Environment, 654, 850-862.

Wu, C.H., Huang, G.R. and Yu, H.J., 2015. Prediction of extreme floods based on CMIP5 climate models: a case study in the Beijiang River basin, South China. Hydrology and Earth System Sciences, 19(3), 1385-1399.

Wu, C., Xian, Z. and Huang, G., 2016. Meteorological drought in the Beijiang River basin, South China: current observations and future projections. Stochastic environmental research and risk assessment, 30(7), 1821-1834.

Wu, J., et al., 2013. Establishing and assessing the Integrated Surface Drought Index (ISDI) for agricultural drought monitoring in mid-eastern China. International Journal of Applied Earth Observation and Geoinformation, 23, 397-410.

Xu, K., et al., 2019. Projection and uncertainty of precipitation extremes in the CMIP5 multimodel ensembles over nine major basins in China. Atmospheric Research, 226, 122-137. 
Table 1. Commonly used MD indices and their required data.

\begin{tabular}{lll}
\hline Drought index & Data needed & Reference \\
\hline Standardized precipitation index (SPI) & Precipitation & McKee et al. (1993) \\
Drought area index (DAI) & Precipitation & Bhalme and Moeley (1980) \\
Deciles index (DI) & Precipitation & Gibbs and Maher (1967) \\
Effective drought index (EDI) & Precipitation & Byun and Wilhite (1996) \\
Crop moisture index (CMI) & Precipitation, temperature & Palmer (1968) \\
Standardized precipitation evapotranspiration & Precipitation, temperature & Vicente-Serrano et al. (2010) \\
index (SPEI) & & \\
Palmer drought severity index (PDSI) & Precipitation, temperature & Palmer (1965) \\
\hline
\end{tabular}

* The index can also be used for operational monitoring of agricultural drought as calculations are updated daily. 
Table 2. Classifications of wet and dry conditions using SPI and SPEI indices.

\begin{tabular}{lcc}
\hline \multicolumn{1}{c}{ Classification } & SPI threshold & SPEI threshold \\
\hline Extremely wet & $2.0 \leq$ SPI & $1.83 \leq$ SPEI \\
Severely wet & $2.0<$ SPI $<1.5$ & $1.82<$ SPEI $<1.43$ \\
Moderately wet & $1.49<$ SPI $<1.0$ & $1.42<$ SPEI $<1.0$ \\
Near normal & $-1.0 \leq$ SPI $\leq 1.0$ & $-1.0 \leq$ SPEI $\leq 1.0$ \\
Moderate drought (MoD) & $-1.49<$ SPI $<-1.0$ & $-1.42<$ SPEI $<-1.0$ \\
Severe drought (SD) & $-2.0<$ SPI $<-1.5$ & $-1.82<$ SPEI $<-1.43$ \\
Extreme drought $(\mathrm{ED})$ & SPI $\leq-2.0$ & SPEI $\leq-1.83$ \\
\hline
\end{tabular}


Table 3. General information of the implemented GCM-RCM combinations.

\begin{tabular}{cccccc}
\hline Driving GCM & Institution & $\begin{array}{c}\text { Concentration } \\
\text { scenario }\end{array}$ & $\begin{array}{c}\text { GCM-RCM } \\
\text { acronym }\end{array}$ & & \multicolumn{2}{c}{ Resolution (km) } \\
\cline { 5 - 6 } HadGEM2-ES & Hadley Centre & RCP4.5-RCP8.5 & $\begin{array}{c}\text { HadGEM- } \\
\text { Reg4 }\end{array}$ & GCM-RCM \\
MPI-ESM-MR & Max Planck Institute & RCP4.5-RCP8.5 & MPI-Reg4 & 210 & 20 \\
GFDL-ESM2M & $\begin{array}{c}\text { Geophysical Fluid } \\
\text { Dynamics Laboratory }\end{array}$ & RCP4.5-RCP8.5 & GFDL-Reg4 & 220 & 20 \\
\hline
\end{tabular}


Table 4. Observed drought events during the period 1971-2000. Year: year of event, LD: length of drought, $S$ : average severity (drought intensity), T average air temperature $\left({ }^{\circ} \mathrm{C}\right)$. MoD: moderate drought, SD: severe drought, ED: extreme drought (see Table 2).

\begin{tabular}{|c|c|c|c|c|c|}
\hline Classification & Year & Dry month $(\mathrm{s})^{*}$ & LD & $S$ & $T\left({ }^{\circ} \mathrm{C}\right)$ \\
\hline \multirow{17}{*}{ MoD } & 1973 & 5 & 1 & 1.06 & 17.6 \\
\hline & 1974 & 3 & 1 & 1.35 & 8.8 \\
\hline & 1977 & $6-7$ & 2 & 1.22 & 22.90 \\
\hline & 1979 & $7-9$ & 3 & 1.26 & 22.90 \\
\hline & 1983 & $2-4$ & 3 & 1.32 & 7.77 \\
\hline & 1984 & 12 & 1 & 1.00 & -0.2 \\
\hline & 1985 & $1-2$ & 2 & 1.15 & 0.40 \\
\hline & 1985 & 9 & 1 & 1.09 & 19.7 \\
\hline & 1986 & 8 & 1 & 1.31 & 27.4 \\
\hline & 1988 & 1 & 1 & 1.00 & 2.5 \\
\hline & 1991 & 3 & 1 & 1.11 & 8.6 \\
\hline & 1994 & $3-5$ & 3 & 1.27 & 14.1 \\
\hline & 1994 & $11-12$ & 2 & 1.16 & 3.8 \\
\hline & 1995 & 2 & 1 & 1.2 & 5.6 \\
\hline & 1998 & $11-12$ & 2 & 1.06 & 6.95 \\
\hline & 1999 & 1 & 1 & 1.1 & 4 \\
\hline & 2000 & 10 & 1 & 1.09 & 13.1 \\
\hline \multirow[t]{6}{*}{ SD } & 1974 & $1-2$ & 2 & 1.50 & 0.10 \\
\hline & 1989 & $8-9$ & 2 & 1.67 & 22.85 \\
\hline & 1993 & $11-12$ & 2 & 1.50 & 5.00 \\
\hline & 1994 & 1 & 1 & 1.62 & 4.30 \\
\hline & 1994 & $6-8$ & 3 & 1.71 & 24.30 \\
\hline & 2000 & 12 & 1 & 1.66 & 2.40 \\
\hline \multirow[t]{2}{*}{ ED } & 1989 & $4-7$ & 4 & 2.07 & 20.35 \\
\hline & 1994 & $9-10$ & 2 & 2.01 & 20.55 \\
\hline
\end{tabular}

* 1 : January $-1 \overline{2: \text { December. }}$ 
Table 5. Projected drought events for the period 2016-2040 on the basis of bias-corrected ensemble GCM-RCM combinations under RCP4.5 and RCP8.5 (average of the meteorological stations). See Table 4 for explanation.

\begin{tabular}{lccccc}
\hline Classification & Year & Dry month(s) & LD & $S$ & $T\left({ }^{\circ} \mathrm{C}\right)$ \\
\hline$R C P 4.5$ & & & & & \\
MoD & 2031 & $4-5$ & 2 & 1.14 & 5.5 \\
& 2033 & 10 & 1 & 1.17 & 8.0 \\
& 2036 & 4 & 1 & 1.12 & 4.9 \\
& 2037 & $6-11$ & 6 & 1.27 & 6.5 \\
$\mathrm{SD}$ & 2038 & 3 & 1 & 1.27 & 4.4 \\
& 2037 & 10 & 1 & 1.42 & 6.8 \\
& 2038 & $1-2$ & 2 & 1.53 & 4.1 \\
$R C P 8.5$ & & & & & \\
& 2017 & 1 & 1 & 1.11 & -13.1 \\
& 2017 & 11 & 1 & 1.13 & 18.5 \\
& 2025 & $5-6$ & 2 & 1.16 & 2.2 \\
$\mathrm{MoD}$ & 2027 & 10 & 1 & 1.11 & 24.5 \\
& 2028 & 12 & 1 & 1.01 & 18.6 \\
& 2029 & $1-5$ & 5 & 1.31 & 11.8 \\
& 2036 & $2-3$ & 2 & 1.16 & 25.8 \\
& 2037 & $1-5$ & 5 & 1.21 & 6.1 \\
$\mathrm{SD}$ & 2040 & 6 & 1 & 1.26 & 29.2 \\
& 2016 & $7-12$ & 6 & 1.61 & 13.4 \\
& 2037 & 1 & 1 & 1.57 & 15.2 \\
\hline
\end{tabular}


Table 6. Comparison of seasonal MD using SPEI index for the reference and near future periods.

\begin{tabular}{|c|c|c|c|c|c|c|c|c|c|c|c|c|c|}
\hline \multirow[t]{3}{*}{ Event } & \multirow{2}{*}{\multicolumn{3}{|c|}{$\begin{array}{l}\text { Season } \\
\text { Winter } \\
\text { (Jan-Mar) }\end{array}$}} & \multirow{2}{*}{\multicolumn{3}{|c|}{$\begin{array}{l}\text { Spring } \\
\text { (Apr-Jun) }\end{array}$}} & \multirow{2}{*}{\multicolumn{3}{|c|}{$\begin{array}{l}\text { Summer } \\
\text { (Jul-Sep) }\end{array}$}} & \multirow{2}{*}{\multicolumn{2}{|c|}{$\begin{array}{l}\text { Autumn } \\
\text { (Oct-Dec) }\end{array}$}} & & \multirow[t]{3}{*}{$N^{* *}$} \\
\hline & & & & & & & & & & & & & \\
\hline & $N^{*}$ & $\mathrm{~S}$ & $\begin{array}{l}\mathrm{T} \\
\left({ }^{\circ} \mathrm{C}\right)\end{array}$ & $\mathrm{N}$ & $S$ & $\begin{array}{l}\mathrm{T} \\
\left({ }^{\circ} \mathrm{C}\right)\end{array}$ & $\mathrm{N}$ & $S$ & $\begin{array}{l}\mathrm{T} \\
\left({ }^{\circ} \mathrm{C}\right)\end{array}$ & $\mathrm{N}$ & $\mathrm{S}$ & $\begin{array}{l}\mathrm{T} \\
\left({ }^{\circ} \mathrm{C}\right)\end{array}$ & \\
\hline \multicolumn{14}{|c|}{$1971-2000$} \\
\hline MoD & 7 & -1.18 & 5.4 & 3 & -1.18 & 12.4 & 3 & -1.22 & 23 & 4 & -1.08 & 3.7 & 17 \\
\hline SD & 2 & -1.56 & 2.2 & 0 & - & - & 2 & -1.7 & 23.6 & 2 & -1.6 & 3.7 & 6 \\
\hline ED & 0 & - & - & 1 & -2.07 & 20.4 & 1 & -2.01 & 20.6 & 0 & & & 2 \\
\hline Total & 9 & & & 4 & & & 6 & & & 6 & & & 25 \\
\hline \multicolumn{14}{|c|}{ 2016-2040 RCP4.5 } \\
\hline MoD & 1 & -1.27 & 4.4 & 2 & -1.13 & 2.08 & 1 & 27 & 6.5 & 2 & -1.1 & 7 & 6 \\
\hline SD & 1 & -1.53 & 4.1 & 0 & - & - & 0 & & & 1 & -1.4 & 6.8 & 2 \\
\hline Total & 2 & - & & 2 & & & & & & 3 & & & 8 \\
\hline \multicolumn{14}{|c|}{ 2016-2040 RCP8.5 } \\
\hline MoD & 4 & -1.31 & 7.7 & 1 & -1.16 & 2.17 & 1 & -1.11 & 24.5 & 3 & -1.1 & 20.5 & 9 \\
\hline SD & 1 & -1.57 & 15. & 0 & - & & 1 & -1.61 & 14.6 & 1 & -1.61 & 14.6 & 3 \\
\hline Total & 5 & & & 1 & 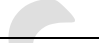 & & 2 & & & 4 & & & 12 \\
\hline
\end{tabular}

* Number of events during a season.

${ }^{* *}$ Total number of evens during the reference/projection period. 


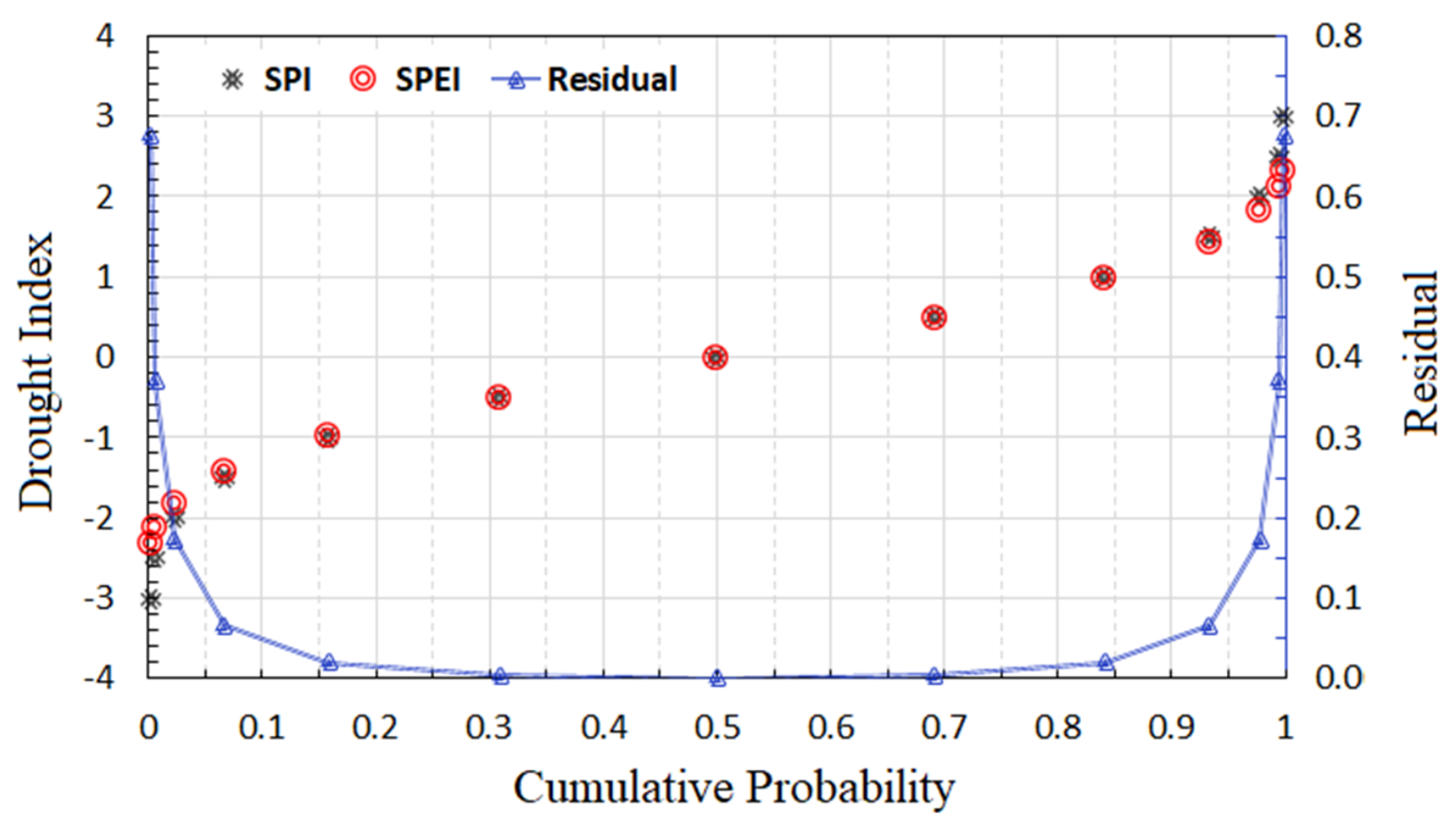

Figure 1. Difference between drought indices for a given probability. 


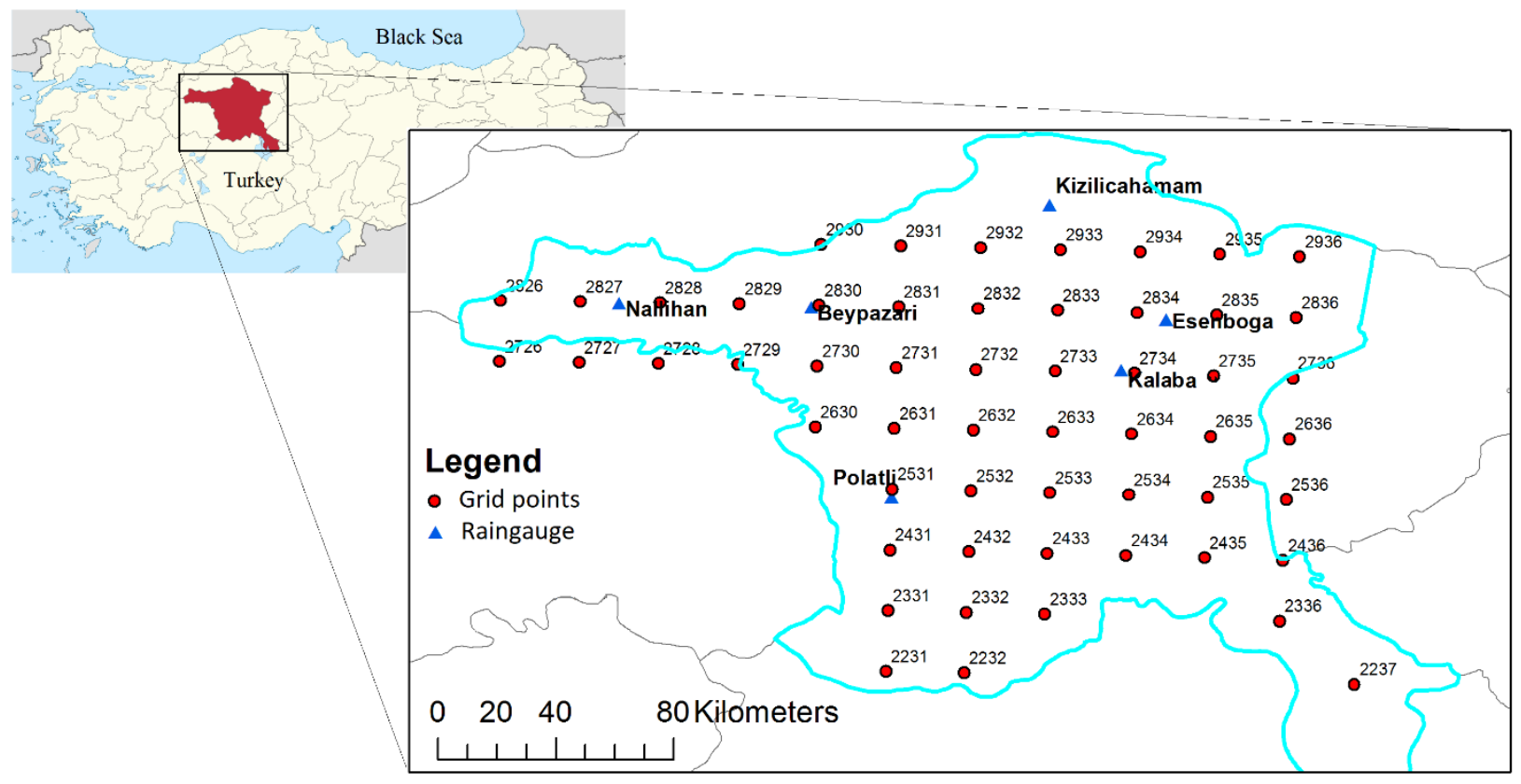

Figure 2. Study area and distribution of observation gauges and regional climate model grid points. 



Figure 3. Evaluation of 3-, 6- and 12-month SPI at the meteorological stations for the reference period (1971-2000). 

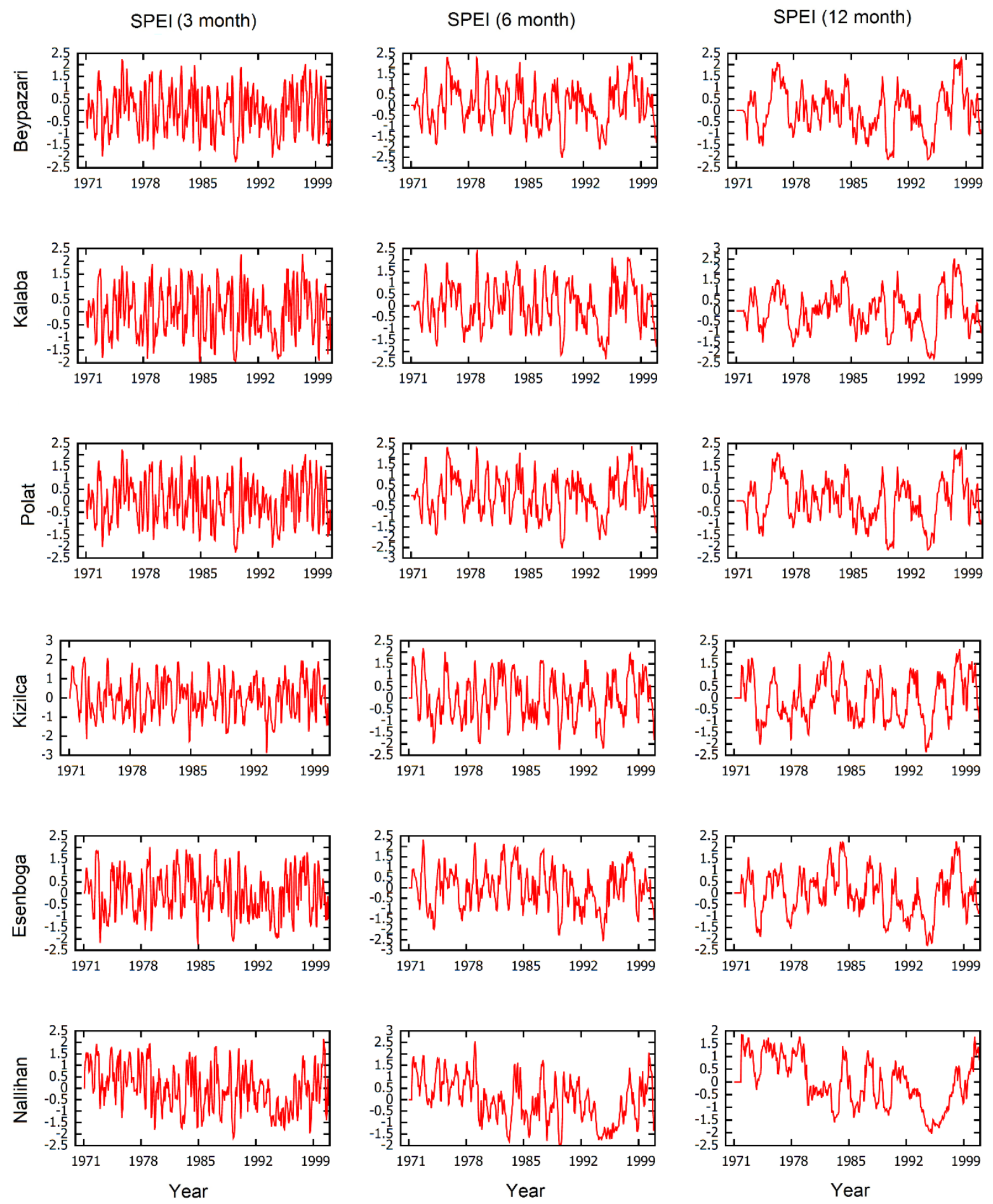

Figure 4. Evaluation of 3-, 6- and 12-month SPEI at the meteorological stations for the reference period (1971-2000). 


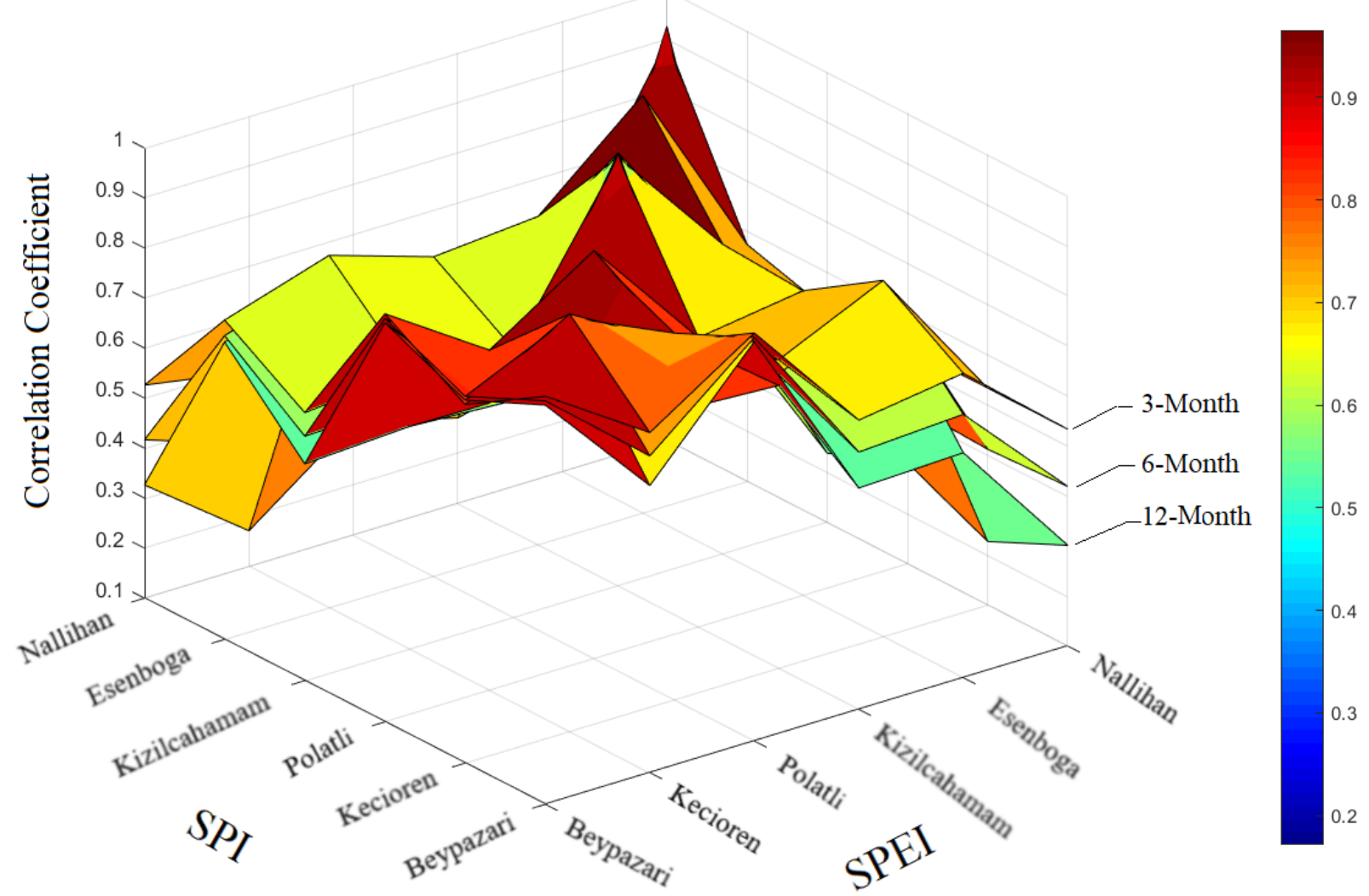

Figure 5. Spatio-temporal variation of Pearson correlation coefficient between MD indices across Ankara. 



Figure 6. Classification of observed drought events for the reference period based on SPEI-6: (a) moderate drought, (b) severe drought and (c) extreme drought events. 



Figure 7. Observed and simulated temperature for the reference period at: (a) Polatli, (b) Kecioren, (c) Nallihan, (d) Beypazari, (e) Esenboga and (f) Kizilcahamam stations. 



•- Observed $\quad$...... HadGEM- Reg4

---- MPI- Reg4 _ - - GFDL- Reg4

Figure 8. Observed and simulated precipitation for the reference period at: (a) Polatli, (b) Kecioren, (c) Nallihan, (d) Beypazari, (e) Esenboga and (f) Kizilcahamam stations. 

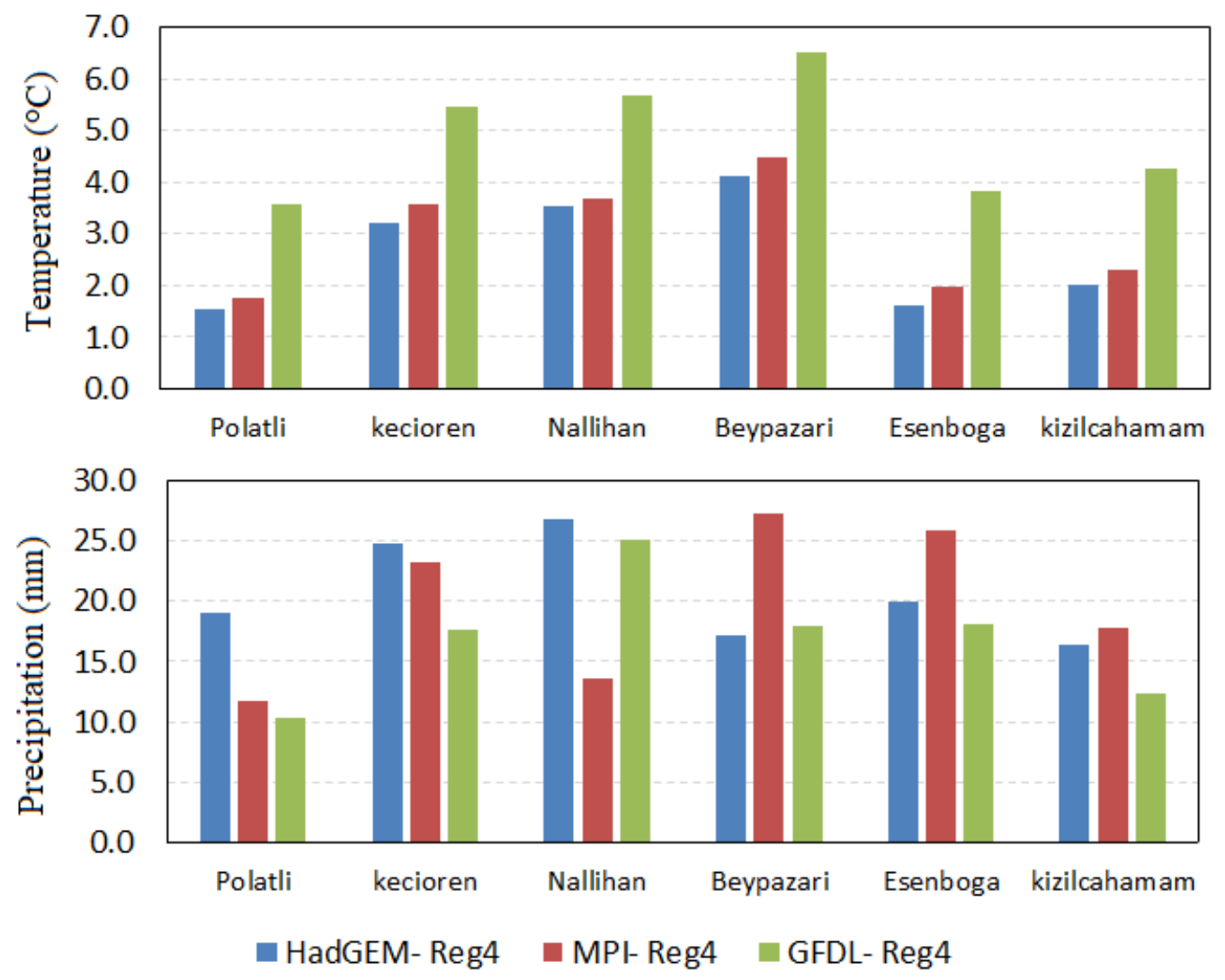

Figure 9. Root mean square error (RMSE) of the GCM-RCM combinations at the studied meteorological stations. 



Figure 10. Examples of cdfs of observed and ensemble simulated monthly temperature (top) and precipitation (bottom) series over the historical period (1971-2000) at Polatli (left) and Kecioren (right) stations. 

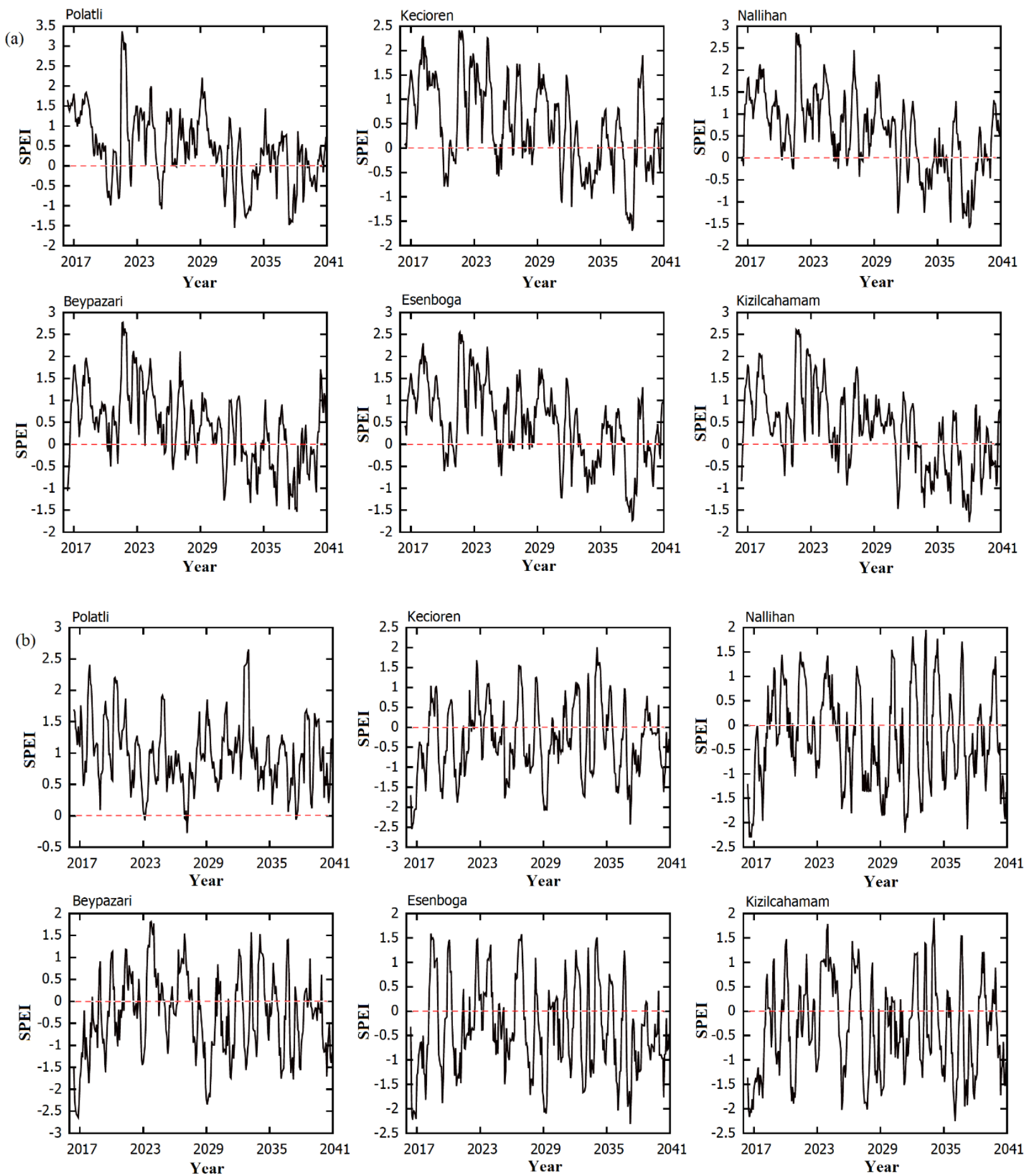

Figure 11. Ensemble projected SPEI-6 at the studied meteorological stations for the near future period (2016-2014): (a) RCP4.5 scenario and (b) RCP8.5 scenario. 

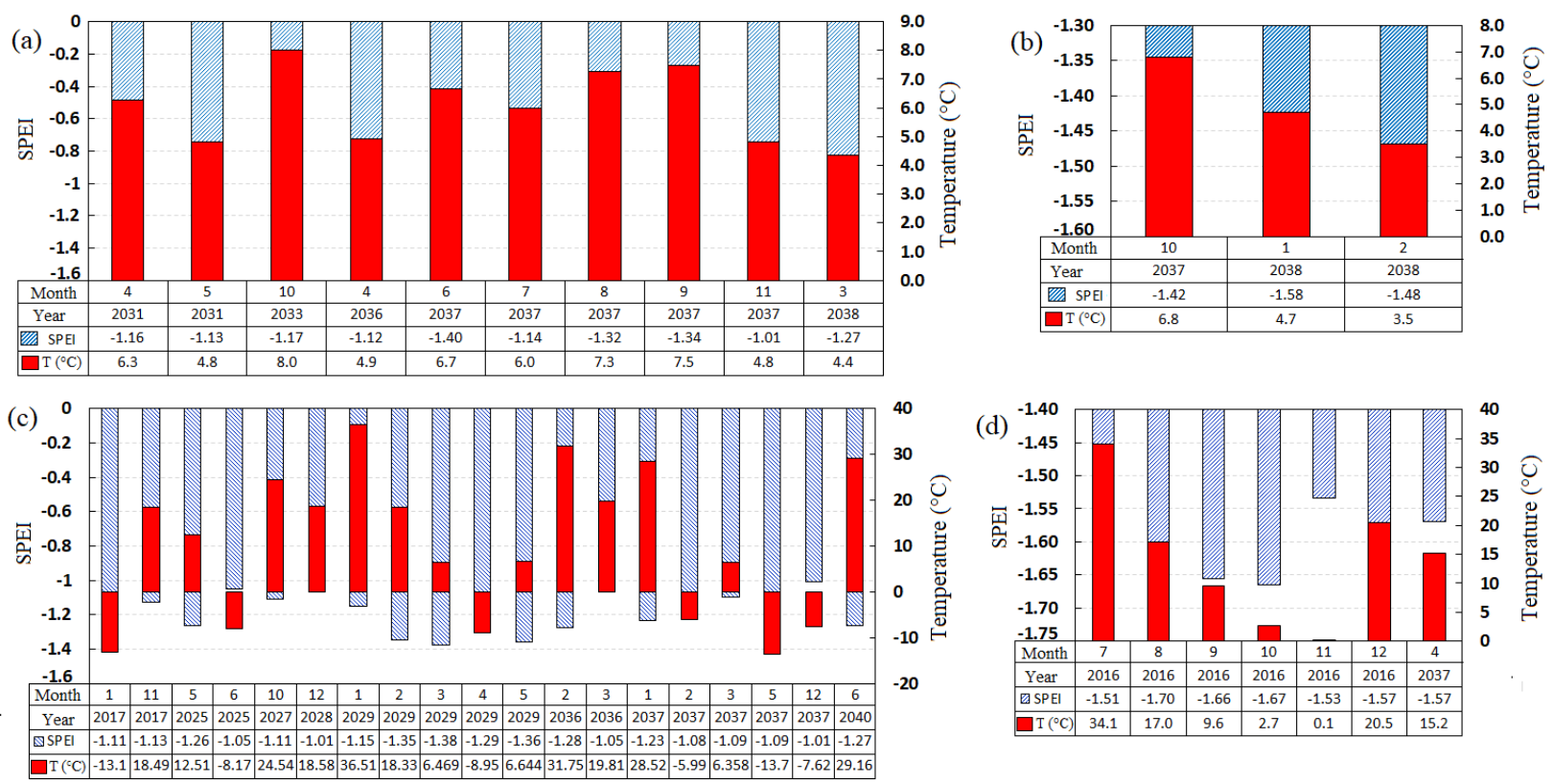

Figure 12. Classification of projected drought events for the period 2016-2040 based on SPEI-6: (a) moderate droughts under RCP4.5 scenario, (b) severe droughts under RCP4.5 scenario, (c) moderate droughts under RCP8.5 scenario and (d) severe droughts under RCP8.5 scenario. 


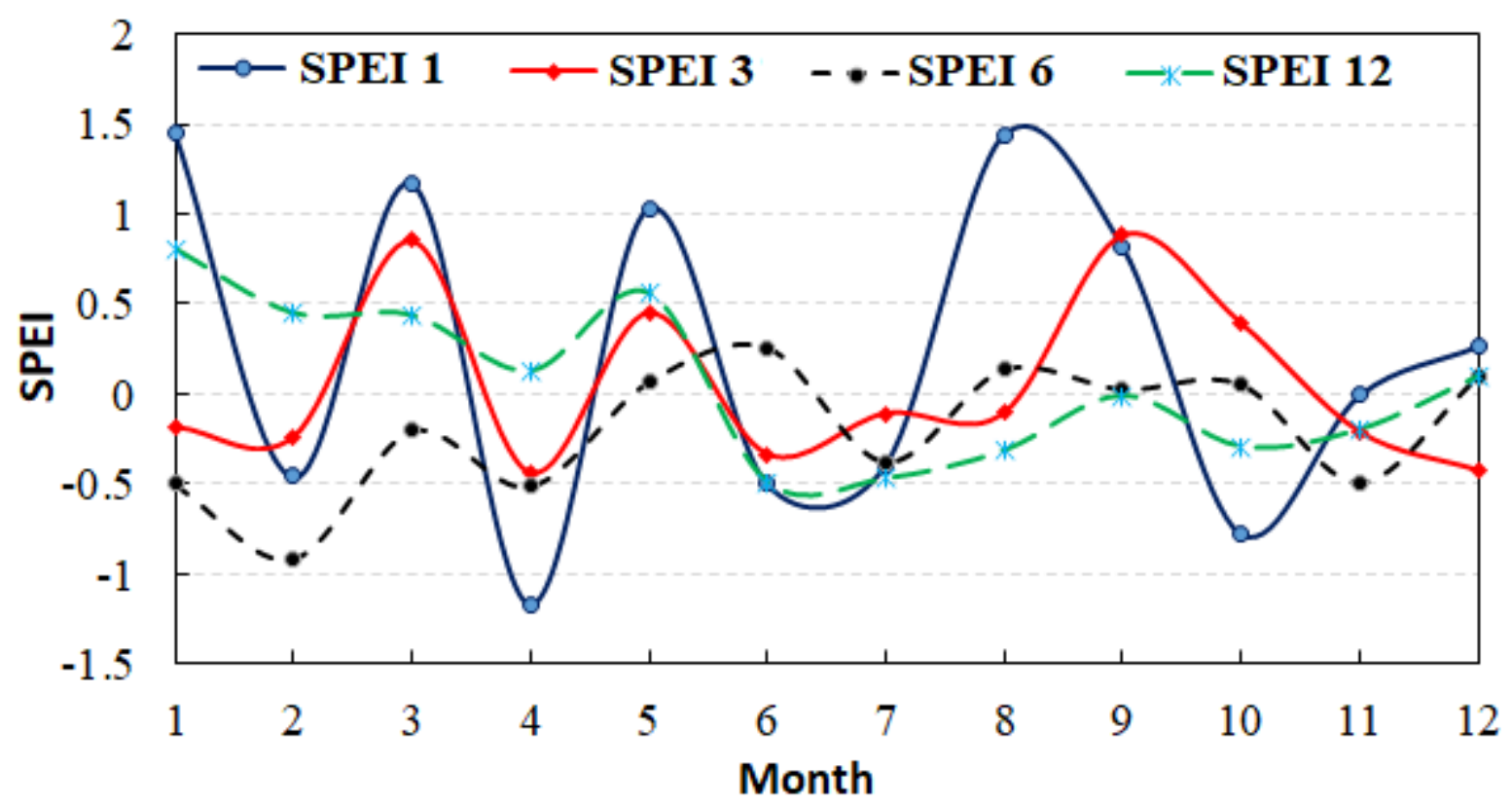

Figure 13. The multi-time scale SPEI index at the studied meteorological stations in Ankara Province based upon the observed temperature and precipitation in 2016. 